\title{
Mouthwash Dosage Form
}

National Cancer Institute

\section{Source}

National Cancer Institute. Mouthwash Dosage Form. NCI Thesaurus. Code C29269.

A solution or suspension intended for oral administration, for its deodorizing or antiseptic

effects in the oral cavity. Usually, the mouthwash is swished around the mouth and expelled. 